\title{
Design and synthesis of new 7-( $N$-substituted-methyl)- camptothecin derivatives as potent cytotoxic agents
}

\author{
Xiao-Bo Zhao ${ }^{a}$, Masuo Goto ${ }^{b}$, Zi-Long Song ${ }^{a}$, Susan L. Morris-Natschke ${ }^{b}$, Yu Zhao ${ }^{b}$, Dan

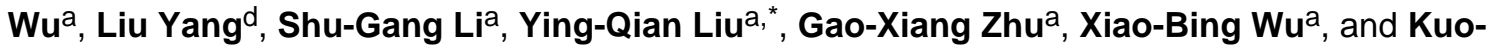 \\ Hsiung Lee ${ }^{b, c, *}$ \\ aSchool of Pharmacy, Lanzhou University, Lanzhou 730000, PR China \\ bNatural Products Research Laboratories, UNC Eshelman School of Pharmacy, University of \\ North Carolina, Chapel Hill, North Carolina 27599 \\ ${ }^{\circ}$ Chinese Medicine Research and Development Center, China Medical University and Hospital, \\ Taichung, Taiwan \\ dEnvironmental and Municipal Engineering School, Lanzhou Jiaotong University, Lanzhou \\ 730000, PR China
}

\section{Abstract}

\begin{abstract}
A series of novel 7-( $N$-substituted-methyl)-camptothecin derivatives was designed, synthesized, and evaluated for in vitro cytotoxicity against four human tumor cell lines, A-549, MDA-MB-231, $\mathrm{KB}$, and KBvin. All of the derivatives showed promising in vitro cytotoxic activity against the tested tumor cell lines, with $\mathrm{IC}_{50}$ values ranging from 0.0023 to $1.11 \mu \mathrm{M}$, and were as or more potent than topotecan. Compounds $9 \mathbf{d}, \mathbf{9 e}$, and $9 \mathbf{r}$ exhibited the highest antiproliferative activity among all prepared derivatives. Furthermore, all of the compounds were more potent than paclitaxel against the multidrug-resistant (MDR) KBvin subline. With a concise efficient synthesis and potent cytotoxic profiles, especially significant activity towards KBvin, compounds $9 \mathbf{d}, \mathbf{9 e}$, and 9r merit further development as a new generation of camptothecin-derived anticancer clinical trial candidates.
\end{abstract}

\section{Keywords}

Camptothecin; Antiproliferative activity; Multidrug resistance

\footnotetext{
(C) 2014 Elsevier Ltd. All rights reserved.

*To whom correspondence should be addressed. Tel.: (919) 962-0066. Fax: (919) 966-3893. khlee@email.unc.edu (K.H. Lee); yqliu@1zu.edu.cn (Y.Q. Liu)..

Publisher's Disclaimer: This is a PDF file of an unedited manuscript that has been accepted for publication. As a service to our customers we are providing this early version of the manuscript. The manuscript will undergo copyediting, typesetting, and review of the resulting proof before it is published in its final citable form. Please note that during the production process errors may be discovered which could affect the content, and all legal disclaimers that apply to the journal pertain.

Supplementary data Supplementary data, including analytical and spectroscopic data for all target compounds, associated with this article can be found, in the online version, at .......
} 
Camptothecin (CPT, 1, Figure 1), a natural quinoline alkaloid isolated by Wall and Wani from the Chinese tree Camptotheca acuminata, showed potent antiproliferative activity against a broad spectrum of tumors. ${ }^{1-3}$ Its antitumor activity is induced by directly binding to topoisomerase I (Topo I), which results in interference with the catalytic cycle of DNATopo I and stabilization of the DNA-Topo I binary complex. ${ }^{4-6}$ Based on CPT's remarkable anticancer activity and unique cytotoxic mechanism, numerous potent CPT analogs have been developed. Among them, two Topo I inhibitors, topotecan (2) and irinotecan (3), have been used successfully in the clinic as anticancer drugs, while several other analogs are the subjects of ongoing preclinical or clinical evaluation. . $^{70}$

Although CPT derivatives remain a promising class of antitumor agents, the highly electrophilic a-hydroxylactone of the E ring is intrinsically unstable and undergoes rapid hydrolysis to the biologically inactive carboxylate form under physiological conditions. ${ }^{11,12}$ This chemical feature diminishes the efficacy of various CPT derivatives in vivo compared to the impressive results often obtained from in vitro studies. Thus, several synthetic strategies to overcome this challenge have been developed, resulting in a logical mapping of the structure-activity relationship (SAR) of CPT derivatives. ${ }^{13,14}$ Substitutions at the 11- or 5-position are not well tolerated, whereas various substituents at the 7-, 9-, or 10-position can improve the antitumor activity, as well as increase E-ring stability. ${ }^{11,15,16}$ In particular, previous studies documented that the introduction of lipophilic substituents at the 7-position provides favorable molecular interactions and improved pharmacological features that could have potential therapeutic advantages. ${ }^{17} \mathrm{~A}$ binding model of CPT with biological macromolecules also indicated that the $\mathrm{C}-7$ molecular area could accommodate considerable structural diversity. ${ }^{18-20}$ On the basis of these critical clues, various substitutions, such as ethyl, alkylsilyl, oxyiminoalkyl, and alkylsilylalkyl, were introduced at the 7-position of CPT to produce potent antitumor agents. To date, 7 -substituted compounds constitute most of the second-generation CPT analogs that have reached preclinical or clinical development studies. Examples include gimatecan (4), ${ }^{21} \mathrm{CKD}-602(5),{ }^{22}$ and BNP-1350 (6), ${ }^{23}$ which contain highly lipophilic substituents intended to increase antitumor activity. These successful examples indicate the important role played by various C-7 substitutions in the activity profiles of CPT analogs and the feasibility of optimizing this compound class through rational C-7 modification.

In our continuing studies on the chemistry of CPT,,${ }^{24-30}$ we recently reported a series of 7ketone camptothecin derivatives with potent antitumor activity and significantly different drug-resistance profiles from those of the parent compound. ${ }^{30}$ Some of the new compounds exhibited activity comparable to that of marketed CPTs, such as $\mathbf{2}$ and $\mathbf{3}$. Notably, some compounds displayed promising cytotoxicity against KBvin cells, while $\mathbf{3}$ lost activity completely. The encouraging preliminary results have prompted us to extend our investigation by synthesizing a novel series of 7 -( $N$-substituted-methyl)-camptothecin derivatives. Herein, we describe our introduction of different nitrogen substituted groups into the 7-position of CPT via a coupling reaction and cytotoxic activity studies on the resulting compounds.

The synthetic route to target CPT derivatives 9a-s is depicted in Scheme 1. Briefly, treatment of $\mathbf{1}$ with hydrogen peroxide and ferrous sulfate in an aqueous methanol-sulfuric 
acid solution furnished 7-hydroxymethylcamptothecin (7) in $80 \%$ yield. ${ }^{31}$ Precursor 7 was converted into the key intermediate 7-bromomethylcamptothecin $(\mathbf{8})$ in $66 \%$ yield by heating in hydrobromic acid. ${ }^{32}$ Intermediate $\mathbf{8}$ was coupled with various substituted amines in dry DMF to afford the desired derivatives 9a-s in $21-46 \%$ yields. ${ }^{33}$ All synthesized target compounds were purified by column chromatography, and their structures were characterized by ${ }^{1} \mathrm{H}-\mathrm{NMR}$, MS, and elemental analysis.

Target compounds 9a-s were evaluated for in vitro cytotoxicity against a panel of human tumor cell lines, including A-549 (lung carcinoma), MDA-MB-231 (triple-negative breast cancer), KB (originally isolated from nasopharyngeal carcinoma), and KBvin (MDR KB subline), using a sulforhodamine B colorimetric (SRB) assay with triplicate experiments. ${ }^{34,35}$ Paclitaxel and $\mathbf{2}$ were used as positive controls and the screening results are shown in Table 1.

As illustrated in Table 1, all new compounds exhibited significant in vitro cytotoxic activity against the four tested tumor cell lines, with $\mathrm{IC}_{50}$ values ranging from 0.0023 to $1.11 \mu \mathrm{M}$, and except for $9 \mathbf{k}, 9 \mathbf{q}$, and $9 \mathbf{s}$, were mostly more active than $\mathbf{2}$, a clinically used CPT-derived chemotherapeutic drug. Compounds 9d, 9e, and 9r were the most potent compounds in the series and were also superior to paclitaxel against the A-549 cell line, which was generally most sensitive to these CPT derivatives. Against the same cell line, many compounds, including 9d-9f, 9h, 9j, 9m-9o, and 9r, also showed better antiproliferative activity than 2 . With few exceptions (i.e., 9k, 9q, and 9s), the tested compounds showed increased cytotoxic potency against the triple-negative breast cancer (MDA-MB-231) cell line compared with 2. With regard to the KB cell line, seven compounds exhibited significant cytotoxic activity comparable to that of $\mathbf{2}$. Remarkably, except for $\mathbf{9 q}$, all of the compounds $\left(\mathrm{IC}_{50} 0.0128-\right.$ $0.274 \mu \mathrm{M})$ were more potent than paclitaxel $\left(\mathrm{IC}_{50:} 1.44 \mu \mathrm{M}\right)$ and $2\left(\mathrm{IC}_{50} 0.396 \mu \mathrm{M}\right)$ against the KBvin subline. These encouraging results suggested that these new derivatives could overcome the MDR phenotype overexpressing P-glycoprotein. Notably, the three most promising compounds 9d, 9e, and 9r showed broad in vitro antitumor spectra and were about 7 - to 20-fold more potent than 2. Further pharmacological, toxicological evaluations and binding affinity analysis with DNA-Topo I target in the modeling of these promising compounds are in progress.

SAR analysis of the results from the synthesized compounds revealed several structural properties that could influence the in vitro cytotoxicity of the new CPT derivatives. Regarding compounds $9 \mathbf{a}$ to $\mathbf{9 j}$ with substituted (phenylamino)methyl groups at C-7, derivatives with $m$ - $/ p$-chlorophenyl rings (9f and 9i) exhibited lower activity than their $o$ substituted isomer $\mathbf{9 j}$. Similarly, the relocation of an electron-donating methoxy group from the $o$-position $\left(9 \mathrm{~d}, \mathrm{IC}_{50} 0.0023 \mu \mathrm{M}\right)$ to the $p$-position $\left(9 \mathrm{c}, \mathrm{IC}_{50} 0.0470 \mu \mathrm{M}\right)$ also decreased the cytotoxicity remarkably. These results suggested that an $o$-substituted phenyl group is more favorable than $m$ - $/ p$-substitued rings for better activity. Moreover 9e and 9f with $p$ fluoro and $p$-chloro substitution, respectively, on the phenyl ring were more potent against A-549 tumor cells than $9 \mathrm{~g}$ with $p$-bromo substitution, indicating that a substituent's size, in addition to position, could affect the activity. However, the presence of a pyridine-2-yl rather than phenyl group on the amine did not substantially change the cytotoxic activity (9l 
vs 9a). Among compounds $9 \mathbf{m}-\mathbf{9 s}$ with non-aromatic amino substituents, the SAR analysis showed that the alkyl variant had an important effect on the in vitro cytotoxic activity. For example, the cytotoxic activity of $9 \mathbf{r}$ with a (propylamino)methyl group at $\mathrm{C}-7$ was significantly greater than that of compounds with a (cyclohexylamino)methyl $(\mathbf{9 m})$ or (diisopropylamino)methyl (9q) moiety. These data suggested that the bulkier substituents in the two latter compounds might produce steric hindrance at the target level and thus lower the cytotoxic activity. The polarity and electron density in the C-7 side chain were also important, as changing the propylamino group in $9 \mathbf{r}$ to a 2-hydroxyethylamino group in $9 \mathrm{~s}$ greatly decreased the cytotoxic activity (e.g., $\mathrm{IC}_{50} 0.0048 \mu \mathrm{M}$ for $9 \mathrm{r}$ vs $0.15 \mu \mathrm{M}$ for $9 \mathrm{~s}$ against A-549). Taken together, these results showed that both the identity and substitution pattern in the R group at C-7 could greatly influence the cytotoxicity of the new CPT derivatives

In summary, 19 novel 7-( $N$-substituted)-methyl-camptothecin derivatives were designed, synthesized, and evaluated for antiproliferative activity against four human tumor cell lines (A-549, MDA-MB-231, KB and KBvin) by using a sulforhodamine B colorimetric assay. Most of the new derivatives showed comparable or superior antiproliferative activity compared with 2. In particular, compounds $9 \mathbf{d}, 9 \mathbf{e}$, and $9 \mathbf{r}$ were the most promising derivatives with 7- to 20 -fold greater potency than 2 against the A-549 cell line and were selected as lead molecules for further development. Notably, with $\mathrm{IC}_{50}$ values ranging from 0.0128 to $1.06 \mu \mathrm{M}$, all of the compounds also were more potent than paclitaxel (IC I0 $_{50} 1.44$ $\mu \mathrm{M})$ against KBvin cells. Furthermore, SAR study indicated that both $\mathrm{N}$-aromatic and $\mathrm{N}$ aliphatic substituents at C-7 can produce potent activity, while selected variation of these substituents can greatly affect the activity. These findings support our further optimization of CPT to develop potential anticancer drug candidates. Continuing studies to substantiate and improve activity profiles are underway in our laboratories and will be reported in due course.

\section{Supplementary Material}

Refer to Web version on PubMed Central for supplementary material.

\section{Acknowledgments}

This work was supported financially by the National Natural Science Foundation of China (30800720, 31371975), the Fundamental Research Funds for the Central Universities (lzujbky-2013-69), and the Foundation of Priority Forestry Disciplines in Zhejiang A\&F University (KF201325). Partial support was also supplied by NIH grant CA177584 from the National Cancer Institute awarded to K.H. Lee. Thanks are also due to the support of Taiwan Department of Health Cancer Research Center of Excellence (DOH-100-TD-C-111-005).

\section{References}

1. Oberlies NH, Kroll DJ. J. Nat. Prod. 2004; 67:129. [PubMed: 14987046]

2. Slichenmyer WJ, Rowinsky EK, Donehower RC, Kaufmann SH. J. Nat. Cancer Inst. 1993; 85:271. [PubMed: 8381186]

3. Wall ME, Wani MC, Cook CE, Palmer KH, McPhail A, Sim GA. J. Am. Chem. Soc. 1966; $88: 3888$.

4. Hsiang YH, Hertzberg R, Hecht S, Liu LF. J. Biol. Chem. 1985; 260:14873. [PubMed: 2997227]

5. Takimoto CH, Wright J, Arbuck SG. Biochim. Biophy. Acta. 1998; 1400:107. 
6. Pommier Y. Nat. Rev. Cancer. 2006; 6:789. [PubMed: 16990856]

7. Liew ST, Yang LX. Curr. Pharm. Des. 2008; 14:1078. [PubMed: 18473856]

8. Lorence A, Nessler CL. Phytochem. 2004; 65:2735.

9. Thomas CJ, Rahier NJ, Hecht SM. Bioorg. Med. Chem. 2004; 12:1585. [PubMed: 15028252]

10. Lerchen HG. Drugs of the Future. 2002; 27:869.

11. Adams DJ. Curr. Med. Chem. - Anti-Cancer Agents. 2005; 5:1.

12. Tobin PJ, Rivory L. Pl Drug Design Reviews - Online. 2004; 1:341.

13. Verma RP, Hansch C. Chem. Rev. 2009; 109:213. [PubMed: 19099450]

14. Sriram D, Yogeeswari P, Thirumurugan R, Bal TR. Nat. Prod. Res. 2005; 19:393. [PubMed: 15938148]

15. Bom D, Curran DP, Kruszewski S, Zimmer SG, Strode JT, Kohlhagen G, Du W, Chavan AJ, Fraley KA, Bingcang AL, Latus LJ, Pommier Y, Burke TG. J. Med. Chem. 2000; 43:3970. [PubMed: 11052802]

16. Leary JO, Muggia FM. Eur. J. Cancer. 1998; 34:1500. [PubMed: 9893620]

17. Pisano C, De Cesare M, Beretta GL, Zuco V, Pratesi G, Penco S, Vesci L, Foderà R, Ferrara FF, Guglielmi MB, Carminati P, Dallavalle S, Morini G, Merlini L, Orlandi A, Zunino F. Mol. Cancer Ther. 2008; 7:2051. [PubMed: 18645015]

18. Redinbo RR, Stewart L, Kuhn P, Champoux JJ, Hol WGJ. Science. 1998; 279:1504. [PubMed: 9488644]

19. Fan J, Weinstein JN, Kohn KW, Shi LM, Pommier Y. J. Med. Chem. 1998; 41:2216. [PubMed: 9632354]

20. Staker BL, Hjerrild K, Feese MD, Behnke CA, Burgin AB, Stewart L. Proc. Natl. Acad. Sci. U.S.A. 2002; 99:15387. [PubMed: 12426403]

21. Dallavalle S, Ferrari A, Biasotti B, Merlini L, Penco S, Gallo G, Marzi M, Tinti MO, Martinelli R, Pisano C, Carminati P, Carenini N, Beretta G, Perego P, Cesare MD, Pratesi G, Zunino F. J. Med. Chem. 2001; 44:3264. [PubMed: 11563925]

22. Ahn SK, Choi NS, Jeong BS, Kim KK, Journ DJ, Kim JK. J. Heterocycl Chem. 2000; 37:1141.

23. Boven E, Van Hattum AH, Hoogsteen I, Schluper HM, Pinedo HM. Ann. N.Y. Acad. Sci. 2000; 922:175. [PubMed: 11193892]

24. Wang HK, Liu SY, Hwang KM, Taylor G, Lee KH. Bioorg.Med.Chem. 1994; 2:1397-1402. [PubMed: 7788302]

25. Wang HK, Lin SY, Hwang KM, McPhail AT, Lee KH. Bioorg.Med. Chem. Lett. 1995; 5:77.

26. Ohtsu H, Nakanishi Y, Bastow KF, Lee FY, Lee KH. Bioorg. Med. Chem. 2003; 11:1851. [PubMed: 12659771]

27. Ye DY, Shi Q, Leung CH, Kim SW, Park SY, Gullen EA, Jiang ZL, Zhu H, Morris-Natschke SL, Cheng YC, Lee KH. Bioorg. Med. Chem. 2012; 20:4489. [PubMed: 22698783]

28. Yang L, Zhao CY, Liu YQ. J. Braz. Chem. Soc. 2011; 22:308.

29. Liu YQ, Tian X, Yang L, Zhan ZC. Eur. J. Med. Chem. 2008; 43:26104.

30. Liu YQ, Dai W, Wang CY, Morris-Natschke SL, Zhou XW, Yang L, Yang XM, Li WQ, Lee KH. Bioorg. Med. Chem. Lett. 2012; 22:7659. [PubMed: 23102893]

31. Sawada S, Nokata K, Furuta T, Yokokura T, Miyasaka T. Chem. Pharm. Bull. 1991; 39:2574. [PubMed: 1806276]

32. Synthesis of key intermediate 7-bromomethylcamptothecin (8). To a solution of 7hydroxymethylcamptothecin (7) $(300 \mathrm{mg}, 0.80 \mathrm{mmol})$ in $\mathrm{HBr}(40 \%, 40 \mathrm{~mL}), 98 \% \mathrm{H}_{2} \mathrm{SO}_{4}(0.1$ $\mathrm{mL}$ ) was added and the mixture was heated at reflux for $16 \mathrm{~h}$. After completion of the reaction, the solvent was evaporated under vacuum and the residue recrystallized from $\mathrm{MeOH}$ to provide 7bromomethylcamptothecin (8) as a light brown solid (234 mg, 66\% yield). ${ }^{1} \mathrm{H}$ NMR (400 MHz, DMS0- $\left.d_{6}\right) \delta: 0.87(\mathrm{t}, J=7.2 \mathrm{~Hz}, 3 \mathrm{H}, 19-\mathrm{H}), 1.84-1.90(\mathrm{~m}, 2 \mathrm{H}, 18-\mathrm{H}), 5.26\left(\mathrm{~s}, 2 \mathrm{H},-\mathrm{CH}_{2}\right), 5.28(\mathrm{~s}$, $2 \mathrm{H}, 5-\mathrm{H}), 5.45$ (s, 2H, 17-H), $6.50(\mathrm{~s}, 1 \mathrm{H}, 20-\mathrm{OH}), 7.33(\mathrm{~s}, 1 \mathrm{H}, 14-\mathrm{H}), 7.76(\mathrm{t}, J=7.2 \mathrm{~Hz}, 1 \mathrm{H}, 11-$ H), 7.89 (t, $J=7.2 \mathrm{~Hz}, 1 \mathrm{H}, 10-\mathrm{H}), 8.21(\mathrm{~d}, J=8.4 \mathrm{~Hz}, 1 \mathrm{H}, 12-\mathrm{H}), 8.42$ (d, $J=8.4 \mathrm{~Hz}, 1 \mathrm{H}, 9-\mathrm{H})$; MSESI $m / z: 441.4[\mathrm{M}+\mathrm{H}]^{+}$; Anal. Calc. For $\mathrm{C}_{21} \mathrm{H}_{17} \mathrm{~N}_{2} \mathrm{O}_{4} \mathrm{Br}$ : C 57.16\%, H 3.88\%, N 6.35\%. Found: C $57.17 \%$, H $3.88 \%$, N $6.34 \%$. 
33. General synthetic procedure for target compounds 9a-s. To a solution of 7bromomethylcamptothecin $(0.1 \mathrm{mmol})$ in dry DMF $(15 \mathrm{~mL})$, different amines $(0.15 \mathrm{mmol})$ dissolved in toluene $(5 \mathrm{~mL})$ were added and the reaction mixture was stirred at room temperature for $12 \mathrm{~h}$. After the reaction was completed, the mixture was evaporated to dryness and the residue was purified by chromatography on silica gel using $\mathrm{CHCl}_{3} / \mathrm{MeOH}$ as eluant to give 9a-s. Representative analytical and spectroscopic data of 7-(N-(2-methoxyphenylamino)methyl)-(20S)camptothecin (9d). Yield 39\%; m.p. $239-241{ }^{\circ} \mathrm{C} ;{ }^{1} \mathrm{H}$ NMR (400 MHz, DMSO- $\left.d_{6}\right) \delta: 0.85(\mathrm{t}$, $J=7.2 \mathrm{~Hz}, 3 \mathrm{H}, 19-\mathrm{H}), 1.79-1.86(\mathrm{~m}, 2 \mathrm{H}, 18-\mathrm{H}), 3.85\left(\mathrm{~s}, 3 \mathrm{H},-\mathrm{OCH}_{3}\right), 5.01(\mathrm{~d}, J=4.8 \mathrm{~Hz}, 2 \mathrm{H}$, $\left.-\mathrm{CH}_{2}-\right), 5.21(\mathrm{~s}, 2 \mathrm{H}, 5-\mathrm{H}), 5.43(\mathrm{~s}, 2 \mathrm{H}, 17-\mathrm{H}), 5.90(\mathrm{~m}, 1 \mathrm{H}, \mathrm{NH}), 6.35(\mathrm{~d}, J=7.6 \mathrm{~Hz}, 1 \mathrm{H}, \mathrm{Ar}-\mathrm{H})$, $6.52(\mathrm{~s}, 1 \mathrm{H}, 20-\mathrm{OH}), 6.53-6.57(\mathrm{~m}, 1 \mathrm{H}, \mathrm{Ar}-\mathrm{H}), 6.61-6.65(\mathrm{~m}, 1 \mathrm{H}, \mathrm{Ar}-\mathrm{H}), 6.87$ (d, J=8.0Hz, 1H, ArH), $7.30(\mathrm{~s}, 1 \mathrm{H}, 14-\mathrm{H}), 7.72(\mathrm{t}, J=7.2 \mathrm{~Hz}, 1 \mathrm{H}, 11-\mathrm{H}), 7.86(\mathrm{t}, J=7.2 \mathrm{~Hz}, 1 \mathrm{H}, 10-\mathrm{H}), 8.17(\mathrm{~d}$, $J=8.4 \mathrm{~Hz}, 1 \mathrm{H}, 12-\mathrm{H}), 8.49$ (d, J=8.4Hz, 1H, 9-H); MS-ESI $m / z: 484.9[\mathrm{M}+\mathrm{H}]^{+}$; Anal. Calc. For $\mathrm{C}_{28} \mathrm{H}_{25} \mathrm{~N}_{3} \mathrm{O}_{5}$ : C 69.55\%, H 5.21\%, N 8.69\%. Found: C 69.56\%, H 5.23\%, N 8.67\%.

34. Skehan P, Storeng R, Scudiero D, Monks A, McMahon J, Vistica D, Warren JT, Bokesch H, Kenney S, Boyd MR. J. Natl. Cancer Inst. 1990; 82:1107. [PubMed: 2359136]

35. Cytotoxic activity was determined by the sulforhodamine B (SRB) colorimetric assay as previously described. ${ }^{34}$ In brief, the cells $(4,000-7,500$ cells/well) were seeded with various concentrations of samples in 96-well plates filled with RPMI-1640 medium containing $10 \mathrm{mM} \mathrm{HEPES}$ and $2 \mathrm{mM}_{\mathrm{L}-}$ glutamine (HyClone) supplemented with $10 \%$ fetal bovine serum (HyClone), $100 \mu \mathrm{g} / \mathrm{mL}$ streptomycin, $100 \mathrm{IU} / \mathrm{mL}$ penicillin, and $0.25 \mu \mathrm{g} / \mathrm{mL}$ amphotericin B (Cellgro). After $72 \mathrm{~h}$ incubation at $37{ }^{\circ} \mathrm{C}$ with $5 \% \mathrm{CO}_{2}$ in air, the living cells were fixed in $10 \%$ trichloroacetic acid for $30 \mathrm{~min}$ followed by staining with $0.04 \%$ SRB (Sigma Chemical Co.) for $30 \mathrm{~min}$. The bound SRB was solubilized with $10 \mathrm{mM}$ Tris-base and the absorbance was measured at $515 \mathrm{~nm}$ using a Microplate Reader ELx800 (Bio-Tek Instruments, Winooski, VT) operated by a Gen5 software. All results were representative of three or more experiments and $\mathrm{IC}_{50}$ is expressed as the average with standard deviation (SD). 

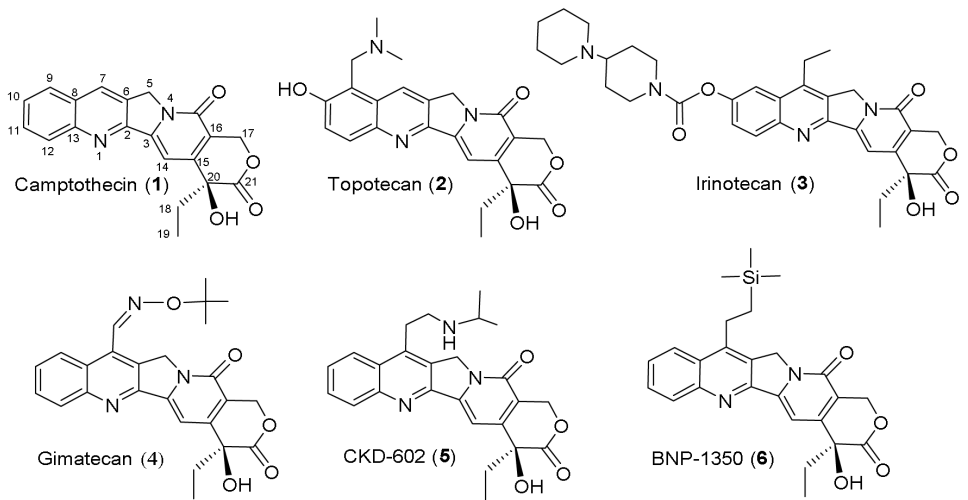

Figure 1.

Structures of camptothecin (1), topotecan (2), irinotecan (3), gimatecan (4), CKD-602 (5), and BNP-1350 (6). 

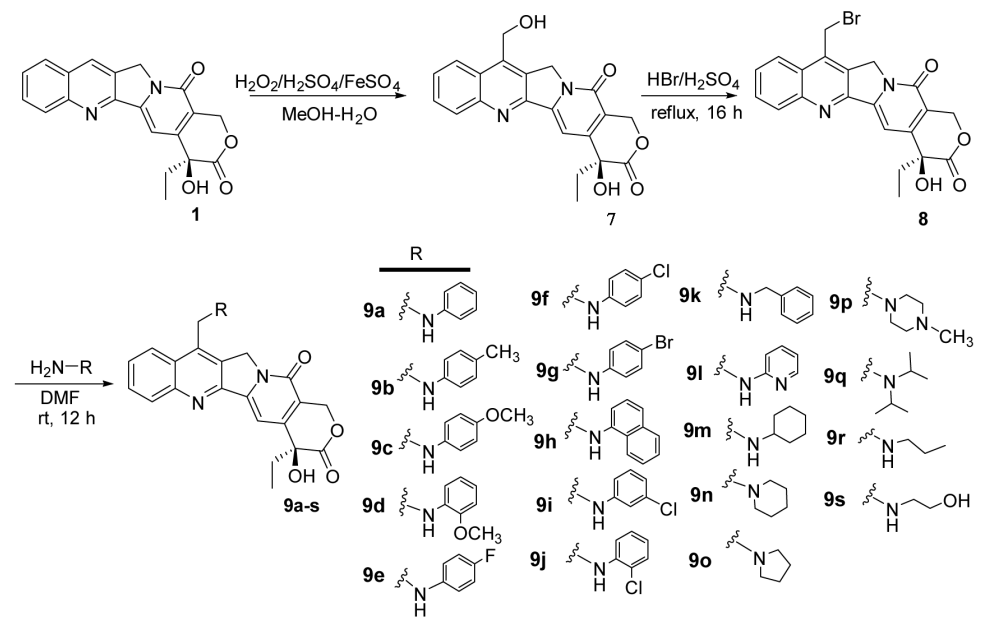

Scheme 1.

Synthesis of target compounds 9a-s. 
Table 1

Antiproliferative activity of $\mathbf{9 a - s}$ against four human tumor cell lines

\begin{tabular}{|c|c|c|c|c|}
\hline \multirow{2}{*}{ Compd } & \multicolumn{4}{|c|}{$\mathrm{IC}_{50}(\mu \mathrm{M})$ with SD } \\
\hline & A-549 & MDA-MB-231 & KB & KBvin \\
\hline $9 a$ & $0.0532 \pm 0.0226$ & $0.0781 \pm 0.0178$ & $0.0783 \pm 0.0272$ & $0.0479 \pm 0.0126$ \\
\hline $9 b$ & $0.0587 \pm 0.0262$ & $0.0927 \pm 0.0187$ & $0.0817 \pm 0.0201$ & $0.0795 \pm 0.0411$ \\
\hline $9 c$ & $0.0470 \pm 0.0191$ & $0.0842 \pm 0.0062$ & $0.0758 \pm 0.0107$ & $0.0773 \pm 0.0255$ \\
\hline 9d & $0.0023 \pm 0.0024$ & $0.0264 \pm 0.0125$ & $0.0046 \pm 0.0032$ & $0.0149 \pm 0.0121$ \\
\hline $9 e$ & $0.0063 \pm 0.0027$ & $0.0300 \pm 0.0163$ & $0.0050 \pm 0.0013$ & $0.0132 \pm 0.0055$ \\
\hline 9f & $0.0391 \pm 0.0173$ & $0.0644 \pm 0.0306$ & $0.0397 \pm 0.0015$ & $0.0129 \pm 0.0066$ \\
\hline $9 \mathrm{~g}$ & $0.0592 \pm 0.0252$ & $0.114 \pm 0.0464$ & $0.0821 \pm 0.0093$ & $0.0633 \pm 0.0177$ \\
\hline $9 h$ & $0.0362 \pm 0.0211$ & $0.0640 \pm 0.0025$ & $0.0615 \pm 0.0119$ & $0.0780 \pm 0.0853$ \\
\hline $9 \mathrm{i}$ & $0.0504 \pm 0.0206$ & $0.0961 \pm 0.0102$ & $0.0713 \pm 0.0139$ & $0.0688 \pm 0.0315$ \\
\hline $9 j$ & $0.0170 \pm 0.0115$ & $0.0576 \pm 0.0514$ & $0.0371 \pm 0.0031$ & $0.0128 \pm 0.0081$ \\
\hline $9 k$ & $0.122 \pm 0.0406$ & $0.337 \pm 0.0114$ & $0.180 \pm 0.0662$ & $0.117 \pm 0.0177$ \\
\hline 91 & $0.0514 \pm 0.0211$ & $0.108 \pm 0.0197$ & $0.0786 \pm 0.0058$ & $0.0706 \pm 0.0217$ \\
\hline $9 m$ & $0.0188 \pm 0.0154$ & $0.0532 \pm 0.0006$ & $0.0362 \pm 0.0153$ & $0.0165 \pm 0.0149$ \\
\hline $9 n$ & $0.0219 \pm 0.0107$ & $0.0699 \pm 0.0043$ & $0.0499 \pm 0.0074$ & $0.0205 \pm 0.0141$ \\
\hline 90 & $0.0155 \pm 0.0059$ & $0.0609 \pm 0.0096$ & $0.0371 \pm 0.0018$ & $0.0208 \pm 0.0199$ \\
\hline $9 p$ & $0.0622 \pm 0.0168$ & $0.110 \pm 0.0177$ & $0.0895 \pm 0.0231$ & $0.274 \pm 0.1592$ \\
\hline $9 q$ & $0.534 \pm 0.0701$ & $1.11 \pm 0.0059$ & $0.813 \pm 0.0556$ & $1.06 \pm 0.0115$ \\
\hline $9 r$ & $0.0048 \pm 0.0042$ & $0.0316 \pm 0.0026$ & $0.0150 \pm 0.0102$ & $0.0217 \pm 0.0157$ \\
\hline $9 \mathrm{~s}$ & $0.150 \pm 0.0275$ & $0.378 \pm 0.0082$ & $0.208 \pm 0.0209$ & $0.183 \pm 0.0219$ \\
\hline 2 & $0.0452 \pm 0.0004$ & $0.102 \pm 0.0055$ & $0.0625 \pm 0.0042$ & $0.396 \pm 0.0207$ \\
\hline Paclitaxel & $0.0057 \pm 0.0016$ & $0.0066 \pm 0.0018$ & $0.0039 \pm 0.0010$ & $1.44 \pm 0.137$ \\
\hline
\end{tabular}

